\title{
Fractures by Firearms in Conflict Town
}

\author{
Toha Georges Kuyigwa1, Akinja Bitum Uwonda ${ }^{2}$, Ona Longombe Ahuka ${ }^{3}$ \\ ${ }^{1}$ Medical School, Catholic University of Bukavu, Bukavu, Democratic Republic of Congo \\ ${ }^{2}$ Medical School of Mbuji Mayi, Mbuji Mayi, Democratic Republic of Congo \\ ${ }^{3}$ Medical School of Kisangani, Kisangani, Democratic Republic of Congo \\ Email: kuyigwa2002@yahoo.fr
}

Received 21 March 2015; accepted 10 May 2015; published 12 May 2015

Copyright (C) 2015 by authors and Scientific Research Publishing Inc.

This work is licensed under the Creative Commons Attribution International License (CC BY). http://creativecommons.org/licenses/by/4.0/

(c) (i) Open Access

\begin{abstract}
For nearly two decades, the eastern Democratic Republic of Congo (DRC) has been plagued by war and abnormal movement of firearms is commonplace. The consequence of this is the increasing number of victim patients from gunshot wound at the hospitals. The aim of this study is to make an assessment of fractures caused by firearms and their management in a post conflict town. This is a retrospective, descriptive, multicenter study involving 123 cases with 128 fractures by firearms recorded during a period of 24 months from $1^{\text {st }}$ January 2011 to $31^{\text {st }}$ December 2012 . Patients were recruited from 3 major hospitals in Bukavu town having a unit of fractures management. One hundred and six $(86.9 \%)$ patients were males with the modal age in the ranks from 20 to 40 years old (mean 29.9 years). Seventy-one $(57.7 \%)$ were civilians and $52(42.3 \%)$ patients were soldiers; $86(78.2 \%)$ came from countryside. The reprisal was implicated in $77(62.6 \%)$ cases. In $62.5 \%$ of cases, fractures were localized in the lower limbs and were treated orthopedically in $50 \%$ of cases. The gunshot fractures in eastern DRC were mainly concerning the civilian young people living in the countryside and necessarily affected the bones of low limb. A study on fracture by firearms should be carried in the area where people have been wounded. Reducing the flow of gunshot could reduce the rate of fractures by firearms.
\end{abstract}

\section{Keywords}

Fracture by Firearms, Post Conflict, Young Subjects, DRC

\section{Introduction}

Trauma by firearms has become more frequent across the world [1]. A study conducted in Mexico from 2008 to 2010 was an increase of $800 \%$ bullet injuries [2]. In the UK, the rate of injuries from firearms grew by $30 \%$ from 1998 to 2000 [3]. These injuries by firearms occur in contexts that differ from one region to another: crime [3], armed conflicts [1] [4]-[6] and the socio-political events [4]-[6]. 
Since the mass arrival of Rwandese refugees in the Eastern Democratic Republic of Congo (DRC) in 1994, successive wars were taking place for the sake of liberation. Due to the proliferation of foreign and national armed groups, surgeons practicing in this part of the country regularly received patients wounded by firearms. These lesions, dominated by open fractures, often complex in terms of bone crash, loss of soft tissue lesions and association, are a challenge for the clinician. In our working conditions characterized by a lack of technical equipment on one hand and the poverty of the population on the other hand, the management of these lesions poses real problems [7] [8].

The present work aims to take state's place into account to encourage policy makers to provide hospitals in appropriate equipment in charge of fractures firearms taken and increase actions to restore peace in this part of the country.

\section{Methodology}

\subsection{Type of Study}

This is a retrospective, descriptive and multicenter study involving gunshot fractures recorded during a period of 24 months from $1^{\text {st }}$ January 2011 to $31^{\text {st }}$ December 2012. Patients were recruited from three major hospitals in Bukavu with a dosage unit in charge of fractures: Provincial General Hospital of Bukavu Reference (PGHBR), the General Hospital of Panzi Reference (GHPR) and the General Hospital of Ciriri Reference (GHCR). Surgical departments of these 3 hospitals have trauma and orthopedics services overseen by a musculoskeletal surgeon. The hospital's records, registers and the operating protocols constituted the bulk of our documentation. All patients underwent surgical debridement, a double antibiotic therapy and tetanus prophylaxis. Surgical debridement consisted of removing of all devitalized tissue, extraction of foreign bodies, perfect hemostasis, copious irrigation with tap water until the wound becomes clean. Depending on the evolution of the wound, delayed primary closure to the $5^{\text {th }}$ postoperative day or skin grafting were provided, if necessary, the option of a directed healing was adopted.

\subsection{Environment Study}

Bukavu, county city of South Kivu Province in the Eastern D.R.C is $2000 \mathrm{~km}$ far from Kinshasa, the capital of the country. It has three hospitals which play the role of reference for the whole of South Kivu Province. South Kivu has an estimated total population of 6.660 .057 inhabitants and an area of $65.128 \mathrm{~km}^{2}$. The average density is estimated at 102 inhabitants $/ \mathrm{km}^{2}$. The province shares borders in its Eastern part with 3 countries: Rwanda, Burundi and Tanzania. The South Kivu has experienced economic destabilization following the recurrent wars that led to the destruction of basic social infrastructure and production units.

\subsection{Population Study}

\subsubsection{Inclusion Criteria}

We have included in this study all patients admitted to these 3 hospitals for gunshot fracture during the period of our study with a complete medical records.

\subsubsection{Exclusion Criteria}

All hospitalized patients with the fracture had occurred before our study period and patients without medical records were excluded from this study.

In total, we selected 123 cases with 128 fractures by firearms from 3 medical training hospitals whereby our study has selected; 91 (74\%) from the PGHBR, 22 (17.9\%) from the GHPR and 10 (8.1\%) from the GHCR. We analyzed the following parameters: age, sex, residence, status (civilian or soldier), circumstances of occurrence of the wounded, and the affected segment, the mode of treatment, the incidence of infection, and the outcome. Regarding the circumstances of occurrence of the trauma, the confrontation implies the exchange of fire among two or more armed factions while the reprisal expresses revenge of a faction or more armed factions on the population. Informed consent was signed by our patients before any intervention.

\subsection{Statistical Analysis}

We used the Epi-Info Version 3.5.4 software for encoding data and analysis. Study variables were gender, resi- 
dence status; circumstances of trauma; the affected body part, the occurrence of complications, evolution (cured, death and abandonment); the management mode of the trauma and age was categorized into four strata: 0 - 22 years, 21 - 40 years, 41 - 60 years, and the class of more than 60 years. For the gender variable, sex ratio was calculated. We performed the usual descriptive statistics, the mean and standard deviation for the age variable and proportions for categorical and discreet variables.

\section{Results}

\subsection{Socio-Demographic Characteristics of Fractured by Firearms in the City of Bukavu 2011-2012}

The average age of our patients was 29.96 years old and 106 (86.2\%) were aged less than 40 years old. Gunshot fractures affect more males with 106 (86.2\%) with a sex ratio of 6:1. Eighty-six (69.9\%) as a residence territories surrounding the Bukavu town and neighbour provinces while 27 (21.9\%) are urban dwellers (Table 1). Seventy-one (57.7\%) are civilians and 52 (42.3\%) patients were military. Reprisal is the most common circumstance in which the fracture occurred with 77 (62.6\%), while confrontation is 46 cases (37.4\%) (Table 1).

\subsection{Part of the Body Affected by the Injury and Treatment Mode in Bukavu Town in 2011-2012}

Fractures are localized in the lower limbs in 80 (62.5\%) patients and upper limbs in 37 (28.9\%) patients, thorax and head are involved in less than $5 \%$ each one. Fractures of long bones by firearms were being treated orthopedically in 64 (50\%) cases, surgically by external fixation in 31 (39.8\%) cases and $2(1.6 \%)$ patients underwent amputation. Six (4.7\%) thoracic drainages were provided and 5 (3.9\%) patients had only a debridement followed by primary suture (Table 2).

\subsection{Evolution of Fractured by Firearms in Bukavu Town in 2011-2012}

Nine cases (7.3\%) were complicated by osteitis (Scheme 1$)$ and we recorded $1(0.8 \%)$ death (Scheme 2).

Table 1. Socio-demographic characteristics of fractured by firearms in Bukavu town 2011-2012.

\begin{tabular}{|c|c|c|c|}
\hline Settings & $\mathrm{n}$ & $\%$ & Average (SD) \\
\hline \multicolumn{4}{|l|}{ Age (years) } \\
\hline $00-20$ & 21 & 17.1 & $29.96 \pm 1.05$ \\
\hline $21-40$ & 85 & 69.1 & \\
\hline $41-60$ & 14 & 11.4 & \\
\hline More than 60 & 3 & 2.4 & \\
\hline \multicolumn{4}{|l|}{ Sex } \\
\hline Male & 106 & 86.2 & \\
\hline Female & 17 & 13.8 & \\
\hline \multicolumn{4}{|l|}{ Residence } \\
\hline Country side & 96 & 78.0 & \\
\hline County town & 27 & 22.0 & \\
\hline \multicolumn{4}{|l|}{ Statue } \\
\hline Civilian & 71 & 57.7 & \\
\hline Military & 52 & 42.3 & \\
\hline \multicolumn{4}{|c|}{ Circumstances of trauma } \\
\hline Reprisal & 77 & 62.6 & \\
\hline Confrontation & 46 & 37.4 & \\
\hline
\end{tabular}


Table 2. Parts of the body affected by the injury and treatment mode.

\begin{tabular}{ccccccc}
\hline \multicolumn{7}{c}{ Mode of treatment } \\
\hline Parts of the body & Orthopedic treatment & External fixation & Amputation & Pleural drainage & Debridement alone & TOTAL \\
Higher limb & 22 & 13 & 2 & & $37(28.9 \%)$ \\
Lower limb & 42 & 38 & & 5 & $80(62.5 \%)$ \\
Head & & & 6 & $5(3.9 \%)$ \\
Thorax & $64(50 \%)$ & $51(39.8 \%)$ & $2(1.6 \%)$ & $6(4.7 \%)$ & $5(3.9 \%)$ & $6(4.7 \%)$ \\
TOTAL & & & & & \\
\end{tabular}

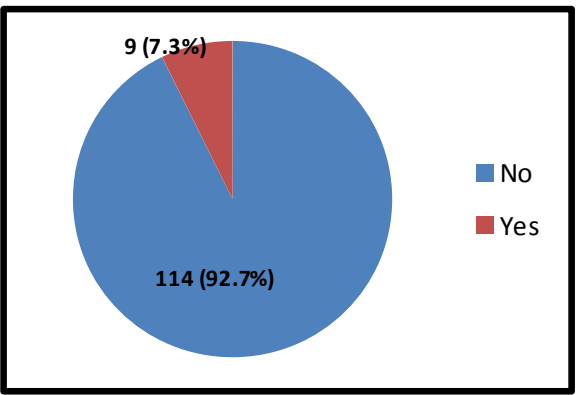

\section{Scheme 1. Occurence of infection.}

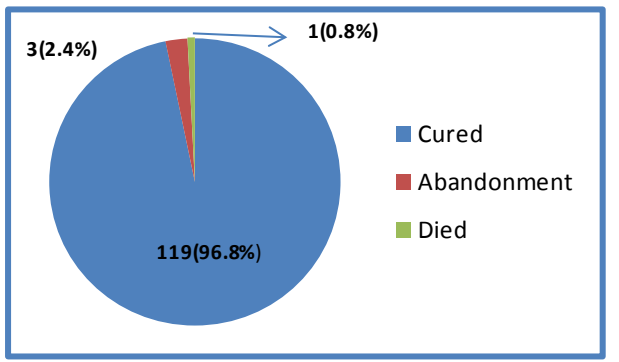

Scheme 2. Outcome of patients.

\section{Discussion}

Our study concerned the too young subjects with a mean age of 29.9 years. Nearly $70 \%$ are aged between 21 and 40 years. Our results are similar to those reported by other authors [2] [3] [5]. Population study of Saidi is relatively older than ours because they record an average age of 39.12 years and a peak between 40 and 49 years [9]. The young age of the population of our study can be explained by the socio-economic situation and endemic activism facing the Eastern DRC. In this age, in order to ensure the survival of their families, young man are engaged in different activities including trade and exploitation of minerals. In this environment of insecurity, they are regularly subjected to be attacked by armed men to extort their properties. Besides this age, we find the loyalist militaries, youths recruited by the lords of war and the self-defense groups.

About sex, men predominate significantly (86.2\%), with a sex ratio of 6:1. Male dominance firearms trauma is emphasized by other authors. It is $100 \%$ for Sarre [5] and 99.9\% in the Hugenberg [10]. Saidi notes a sex ratio of 10:1 [9] while Moye-Elizalde GA records a sex ratio of 27:1 [2].

Regarding victims’ residences, most of them 96 (78.2\%) are coming from the countryside. Bukavu, the county town of the South-Kivu Province and hosting state institutions is relatively secured. Nevertheless, the different lords of war are spread over the rest of the countryside which explains high proportion of victims' number coming from countryside.

Concerning the victims' statue, it emerges that civilians cases are more concerned than the militaries one with $71(57.7 \%)$ cases. The relatively high proportion of civilians is related to insecurity result of traffic abnormal 
firearms. Our results differ from those found by Saare in Bissau, for whom all of their injuries consisted of the militaries [5]. Moye-Elizalde in Nigeria [2] and Dogba in Ivory Coast [4] also noted a predominance of civilians.

In our study the circumstances of fracture's occurrence are represented by reprisal. For Dogba in Ivory Coast, gunshot fractures are the work of the militaries to restore order during sociopolitic demonstrations [4] while Saidi in Kenya criminalize attacks perpetrated by thieves [9].

The lower limbs are most affected by ballistic fractures in our study. This distribution of lesions in gunshot injuries differs from one author to another. For Owen, fractures by firearms are equitably distributed to lower and higher limbs [11]. However, other authors confirm the predilection of gunshot injuries to the lower limbs [1] [2] [9] [12] [13]. This preponderance of lower limbs fractures can be explained by their low lethality compared to lesions of the head and trunk which kill quickly on the field and are not recorded in the structures of care [9] [14].

When receiving patients, we gave them double antibiotics and tetanus prophylaxis. The type of antibiotic and duration of administration is the subject of different opinions as regarding the literature. It is a short-term antibiotic prophylaxis instituted early for Ducourau [15] and Bowyer [16]. Rump [17] and Tejan [18], recommend prehospital antibiotics intent of curative at the time of evacuation patient as soon as possible.

Debridement and irrigation are essential practices in the management of traumatic injuries by firearms [1] [8] [11] [18]. Keeling restored an irrigation at least 9 liters of physiologic serum per wound [12]. This generous irrigation with physiologic serum is not affordable in our working conditions due to the lack of our patients' means. Cleaning the wound by using tap water could also give a significant service. A delayed primary suture and skin grafts has led to the healing of soft tissues as recommended by other authors [12] [14] [16] [17].

Concerning the treatment of long bones, we have focused on orthopedic procedures in 64 (50\%) due to the lack of external fixators. However, for some cases external fixation was performed, attitude advocated by some authors [4] [12] [19]. Yet osteosynthesis with implants is increasingly used to treat open gunshot fractures [2] [4] [12] [19]. In a total of 559 fractures, Moye-Elizalde resorted to conservative treatment in $44.3 \%$ of cases, the external fixator in $37 \%$ of cases, the plate screwed in $21 \%$ and intramedullary nailing in $17 \%$ of cases [2].

We found $9(7.3 \%)$ cases of osteitis. This infection rate is close to the results of Keeling (8\%) [12] and Moye-Elizalde (6\%) [2], but is far inferior to those reported by Saidi (35.5\%) [9] and Lambert (60\%) [13]. Lin does not store any infection in his study [20]. Infection ballistic fractures depend on several factors including delay and quality of support [16].

We regretted $1(0.8 \%)$ death. The mortality rate was $7.72 \%$ for Moye-Elizalde [2] and 5.6\% for Saidi [9]. Our very low mortality rate does not reflect the reality because firearm's victims with bad prognosis die before reaching a medical training and are not therefore recorded [2] [10].

\section{Conclusion}

On account of the abnormal movement of gunshot, fractures by firearms occurring in the eastern DRC are frequently recorded in care institutions of Bukavu. They concern young males living in the rural areas in most civil cases and occur in a context of reprisal. They mainly affect the bones of the lower limbs and the management of these fractures is mainly orthopedic. A study on fracture by firearms should be carried in the area where people have been wounded. Reducing the flow of gunshot could decrease the rate of fractures by firearms.

\section{References}

[1] Dougherty, P., Vaidya, R., Silverton, C., Bartlett, C. and Najibi, S. (2009) Joint and Long-Bone Gunshot Injuries. Journal of Bone and Joint Surgery, 91, 980-997.

[2] Moye-Elizalde, G.A., Ruiz-Martínez, F., Suarez-Santamaría, J.J., Ruiz-Ramírez, M., Reyes-Gallardo, A. and DíazApodaca, B.A. (2013) Epidemiology of Gunshot Wounds at Ciudad Juárez, Chihuahua General Hospital. Acta Ortopédica Mexicana, 27, 221-235.

[3] Persad, I.J., Reddy, R.S., Saunders, M.A. and Patel, J. (2005) Gunshot Injuries to the Extremities: Experience of a U.K. Trauma Centre. Injury, 36, 407-411. http://dx.doi.org/10.1016/j.injury.2004.08.003

[4] Dogba, E., Toure, S., Bé, J., Adibo, G., Vanga, M., Kouamé, A., et al. (2013) Crash Open of the Shaft Femur by Gunshott at the CHU of Cocody, Abidjan (Ivory Coast): About 15 Cases in the Post-Election Political-Military Crisis of 2010. West African Journal of Research for Health, 15-19. 
[5] Sarre, B., Sene, M., Seck, M., Faye, M., Ogougbery, M. and N'diaye, D. (2003) Crash Open of the Limbs by Firearms. Bissau Experience about 53 Cases. Medicine and Memory Army, 31, 67-73.

[6] Labeeu, F., Pasuch, M., Toussaint, P. and Van Erps, S. (1997) Surgical Experience in Africa: The War of Rwanda in October 1990 to August 1993. Belgian Military Medical Annals, 11, 71-77.

[7] Uwonda, A. and Panda, M.B. (2010) The External Minifixation of Bone Ends by Minifixator "K-Digifix". Annals of African Medicine, 3, 419-425.

[8] Panda, M.B. (2005) External Fixation of Bones in the Democratic Republic of Congo. Aggregation Thesis of Higher and University Education, University of Kinshasa, Kinshasa.

[9] Saidi, H.S., Nyakiamo, J. and Faya, S. (2002) Gunshot Injuries as Seen at the Aga Khan Hospital, Nairobi, Kenya. East African Medical Journal, 79, 188-192. http://dx.doi.org/10.4314/eamj.v79i4.8876

[10] Hugenberg, F., Ajango, W., Mwita, A. and Opondo, D. (2007) Firearm Injuries in Nairobi, Kenya. Who Pays the Price? Journal of Public Health Policy, 28, 410-419. http://dx.doi.org/10.1057/palgrave.jphp.3200152

[11] Owens, B., Kragh, J., Macaitis, J., Svoboda, S. and Wenke, J. (2007) Characterization of Extremity Wounds in Operation Iraqi Freedom and Operation Enduring Freedom. Journal of Orthopaedic Trauma, 21, 254-257. http://dx.doi.org/10.1097/BOT.0b013e31802f78fb

[12] Keeling, J., Gwinn, D., Tintle, S., Andersen, R. and McGuigan, F. (2008) Short-Term Outcomes of Severe Open Wartime Tibial Fractures Treated with Ring External Fixation. Journal of Bone and Joint Surgery, 90, 2643-2651. http://dx.doi.org/10.2106/JBJS.G.01326

[13] Lambert, E., Simpson, R., Marzouk, A. and Unger, D. (2003) Orthopaedic Injuries among Survivors of USS COLE Attack. Journal of Orthopaedic Trauma, 17, 436-441. http://dx.doi.org/10.1097/00005131-200307000-00008

[14] Rowley, D.I. (1996) The Management of War Wounds Involving Bone. Journal of Bone and Joint Surgery, 78, 706709.

[15] Ducourau, J.P., Lagnous, J.F. and Cavallo, J.D. (2000) Antibioprophylaxie en chirurgie de guerre. In: Saissy, Ed., Urgences et réanimation en milieu militaire, Arnette, Paris, 233-239.

[16] Bowyer, G.W. and Rossiter, N.D. (1997) Management of Gunshot Wounds of the Limbs. British Editorial Society of Bone and Joint Surgery, 79, 1031-1036. http://dx.doi.org/10.1302/0301-620X.79B6.6977

[17] Rump, A. (2012) The Use of Antibiotics in Prehospital Military Milieu. French Annals of Anesthesia and Intensive Care, 31, 232-238.

[18] Tejan, J. and Lindsey, R.W. (1998) Management of Civilian Gunshot Injuries of the Femur. A Review of the Literature. Injury, 29, SA18-22.

[19] Seng, V.S. and Masquelet, A.C. (2013) Management of Civilian Ballistic Fractures. Orthopaedics \& Traumatology: Surgery \& Research, 99, 953-958. http://dx.doi.org/10.1016/j.otsr.2013.08.005

[20] Lin, D.L., Kirk, K.L., Murphy, K.P., McHale, K.A. and Doukas, W.C. (2004) Evaluation of Orthopaedic Injuries in Operation Enduring Freedom. Journal of Orthopaedic Trauma, 18, 300-305. http://dx.doi.org/10.1097/00005131-200405000-00006 